\title{
Parkinson Hastalığının Derecesi ile Yürüyüş Değişkenliği Arasındaki İlişkinin Bulanık Tekrarlılık Grafiğine Göre Araştırılması
}

\author{
İsmail Cantürk ${ }^{1 *}$ \\ ${ }^{1}$ Yıldız Teknik Üniversitesi, Elektrik Elektronik Fakültesi, Elektronik ve Haberleşme Mühendisliği Bölümü, İstanbul, Türkiye (ORCID: 0000-0003-0690-1873)
}

(İlk Geliş Tarihi 5 Mart 2020 ve Kabul Tarihi 13 Haziran 2020)

(DOI: 10.31590/ejosat.699099)

ATIF/REFERENCE: Cantürk, İ. (2020). Parkinson Hastalığının Derecesi ile Yürüyüş Değişkenliği Arasındaki İlişkinin Bulanık Tekrarlılık Grafiğine Göre Araştırılması. Avrupa Bilim ve Teknoloji Dergisi, (19), 410-419.

\begin{abstract}
Öz
Parkinson hastalığı $(\mathrm{PH})$ beyindeki ilerleyici nöron kaybıyla ilgili olup milyonlarca insanın hayatını olumsuz yönde etkilemektedir. PH'nin tanısı genellikle radyonüklid pozitron yayınlayıcı tomografi veya tek foton emisyonlu bilgisayarlı tomografi gibi bazı klinik testler kullanılarak dopaminerjik nöronlardaki düşüşün belirlenmesine dayanır. Bununla beraber hastalığa uzaktan tanı koyulabilmesine yönelik çeşitli çalışmalarda literatürde yer almaktadır. PH'yi engelleyen veya iyileştiren bir tedavi yöntemi olmamakla birlikte hastalığın çeşitli belirtilerine yönelik kısmi tedaviler uygulanmaktadır. Motor ve motor olmayan belirtiler arasında titreme, sertlik, postüral dengesizlik, depresyon ve kaygı gibi çeşitli faktörler vardır. Bu çeşitli belirtilerle birlikte Parkinson hastalarının yürüyüş değişkenliği gösterdikleri saptanmıştır. Bu çalışmada Parkinson hastalarının yürüyüş verileri incelenerek, PH’nin derecesi ile yürüyüş değişkenliği arasındaki ilişki ortaya konmuştur. Yürüyüşs sinyalleri tek boyutlu sinyaller şeklinde olup bu veriler bulanık tekrarlılık grafiği yöntemi ile görselleştirilmiştir. Bulanık tekrarlılık grafiği ile zaman serisi şeklindeki sinyaller dokusal bilgiler içeren resme dönüştürülmüştür. Görselleştirilen verilerde gri seviyeli eş-zamanlılık matrisi kullanılarak otokorelasyon, kontrast, korelasyon, küme önceliği, küme gölgesi, benzeşmezlik, enerji, entropi, homojenlik ve maksimum olasılık parametreleri hesaplanmıştır. Hesaplanan parametrelerin PH değerleme ölçekleri olan Hoehn\&Yahr, UPDRS ve MDS-UPDRS ile ilişkisi araştırılmıştır. Elde edilen sonuçlara göre otokorelasyon, küme önceliği, enerji, entropi, ve maksimum olasılık parametreleri tüm değerleme ölçekleri ile korele olduğu saptanmıştır. Bunlardan entropi pozitif korelasyon gösterirken, diğerleri negatif korelasyona sahiptir. Korelasyon ve küme gölgesi parametrelerinin ise üç değerleme ölçeği ile de ilişkisi olmadığı belirlenmiştir. Hoehn\& Yahr değerleme ölçeğinin diğer ölçeklere göre genel anlamda daha yüksek sonuçlar ortaya koyması ayırt ediciliğinin daha fazla olduğunu ortaya koymaktadır. Bu çalışmanın yenilikçi yanı yürüyüş değişkenliği ile PH’nin derecesi arasındaki ilişkinin hesaplamalı yöntemlerle ortaya konmasidır.
\end{abstract}

Anahtar Kelimeler: Parkinson hastalığı, Parkinson hastalığının derecesi, Yürüyüş değişkenliği, Bulanık tekrarlılık grafiği, Gri seviyeli eş-zamanlılık matrisi.

\section{Investigation of the Relationship between Severity of Parkinson's Disease and Gait Variability Based on Fuzzy Recurrence Plot}

\begin{abstract}
Parkinson's disease is a neurodegenerative disease that negatively affects millions of lives. The diagnosis of Parkinson's disease is usually based on determining the decrease in dopaminergic neurons using some clinical tests, such as radionuclide positron emission tomography or single photon emission computed tomography. Nevertheless, there are various studies in the literature to diagnose the disease remotely. Although there is no available treatment method yet that prevents or cures Parkinson's disease, partial treatments are applied for various symptoms of the disease. Motor and non-motor symptoms include tremor, stiffness, postural instability, depression, and anxiety. Along with these various symptoms, Parkinson's patients were found to exhibit gait variability. In this study,
\end{abstract}

\footnotetext{
* Sorumlu Yazar: Yıldız Teknik Üniversitesi, Elektrik Elektronik Fakültesi, Elektronik ve Haberleşme Mühendisliği Bölümü, İstanbul, Türkiye, ORCID: 0000-0003-0690-1873, icanturk@yildiz.edu.tr
} 
the gait signals of Parkinson's disease patients were examined and the relationship between severity of Parkinson's disease and gait variability was revealed. Gait signals are one dimensional signals and they were visualized with fuzzy recurrence plot method. Time series signals were converted to images, which contains textural information, by the aid of fuzzy recurrence plot. In the visualized data, autocorrelation, contrast, correlation, cluster priority, cluster shadow, dissimilarity, energy, entropy, homogeneity and maximum probability parameters were computed by using gray level co-occurrence matrix. The relationship between the computed parameters and, Hoehn\&Yahr, UPDRS and MDS-UPDRS, which are rating scales to assess severity of Parkinson's disease, were evaluated. According to the obtained results autocorrelation, cluster priority, energy, entropy, and maximum probability parameters were found to be correlated with all rating scales. Although entropy shows a positive correlation, others have a negative correlation. Correlation and cluster shadow parameters were found to be not related to the rating scales. The fact that the Hoehn\&Yahr rating scale has higher results, reveals that it is more discriminative. The innovative part of this study is demonstration of the relationship between gait variability and the severity of Parkinson's disease with computational methods.

Keywords: Parkinson's disease, Severity of Parkinson's disease, Gait variability, Fuzzy recurrence plot, Gray level co-occurrence matrix.

\section{Giriş}

Parkinson hastalığı $(\mathrm{PH})$ en yaygın görülen nörodejeneratif hastalıklardan olmakla birlikte 65 yaş üstündeki nüfusun \%2-3' ünü etkilemektedir (Poewe et al., 2017). 85 yaşın üstünde ise yaygınlık oranı \%4-5' e ulaşmaktadır (De Lau et al., 2004). Nöropatolojik özellikleri arasında beyinde gözlemlenen nöron kaybı yer almaktadır. Bununla birlikte merkezi ve çevresel sinir sisteminde bulunan birçok hücre tipide hastalığın ilk dönemlerinden itibaren etkilenmektedir (Poewe et al., 2017). Hastalığın belirtileri arasında titreme, sertlik, bradikinezi ve asimetri başlangıcı vardır. İlerleyen dönemlerinde postüral dengesizlik, koku alma duyusunda azalma ve mikrografi gözlemlenir (Italian, 2003). Hastalığın motor belirtilerinin yanında depresyon, ilgisizlik, kaygı, uyku düzensizlikleri, ağrı gibi birçok motor olmayan belirtileri de bulunmakta olup bunlar erken evrelerde de görülebilmektedir (Chaudhuri \& Schapira, 2009). Bazı ön çalışmalar PH’nin ilerlemesinin yavaşlatabileceğini düşündürse de hastalığı engelleyen veya tersine çevirebilen bir yöntem bulunmamaktadır (Rao et al., 2006). Hastalığın belirtileri ise kısmen tedavi edilebilmektedir (Chaudhuri \& Schapira, 2009; Rao et al., 2006)

PH'nin tanısı genellikle radyonüklid pozitron yayınlayıc1 tomografi veya tek foton emisyonlu bilgisayarlı tomografi gibi bazı klinik testler kullanılarak dopaminerjik nöronlardaki düşüşün belirlenmesine dayanır (Conditions, 2006). Bununla beraber hastalığa uzaktan tanı koyulabilmesine yönelik çeşitli çalışmalarda literatürde yer almaktadır (Cantürk \& Karabiber, 2016; Gündüz; Khatamino et al., 2018; C. Yücelbaş \& Ş. Yücelbaş, 2019b; Ş. Yücelbaş \& C. Yücelbaş, 2019). Bu çalışmalarda Parkinson hastalarının sesleri (Sakar et al., 2013; Tsanas et al., 2010; C. Yücelbaş \& Ş. Yücelbaş, 2019a; Yücelbaş, 2020), el yazıları (Afonso et al., 2019; Cantürk, 2020; Naseer et al., 2019) ve yürüyüş değiş̧kenlikleri (T. D. Pham, 2017; Pham \& Yan, 2017) gibi çeşitli verilerle hastalığın belirlenmesine çalışılmıştır.

Parkinson hastalarının sabit bir yürüme ritmine sahip olmadıkları ortaya konmuştur. Bu yürüme bozukluğu adım ve salınım sürelerinde artış olarak belirlenmiştir (Frenkel-Toledo et al., 2005; Frenkel-Toledo et al., 2005). Yürüme hızı artırıldığında salınım ve adım sürelerinin aynı şekilde etkilenmediği gözlemlenmiştir(Frenkel-Toledo et al., 2005). Parkinson hastalarının yürüme esnasında kognitif işlem gerçekleştirdiklerinde yürüyüş değişkenliklerinde artış saptanmıştır (Yogev et al., 2005). Yürüyüş değişkenliği verisi kullanılarak PH'nin belirlenmesine yönelik çeşitli çalışmalar yapılmıştır. Pham (T. D. Pham, 2017) tek boyutlu olan yürüyüş değişkenliği sinyallerini görselleştirerek, nörodejeneratif hastalıklarda doku tabanlı sınıflandırma yapmıştır. Pham vd. (Pham \& Yan, 2017) yürüyüş değişkenliğini kullanarak tensör dekompozisyon yöntemi ile PH'yi tespit etmeye çalıştılar. Abdulhay vd. (Abdulhay et al., 2018) makine öğrenmesi teknikleri kullanarak yürüyüş verisinden PH’yi sınıflandırdılar. Aydın vd. (AYDIN \& Aslan, 2017) dalgacık dönüşüm yöntemini kullanarak yere uygulanan kuvvet sinyallerinden PH gibi nörodejeneratif hastalıkları sınıflamışlardır. Yapılan çalışmalar yürüyüş verisinden PH'nin tespitine yönelik olup, literatürde PH'nin derecesi ile yürüyüş değişkenliği arasındaki ilişkiye dair çalışmaya rastlanılmamıştır.

PH'yi derecelendirmek için temel olarak 3 adet değerleme ölçeği kullanılmaktadır. Bunlar UPDRS (Unified PD Rating ScaleBirleşik PH Değerleme Ölçeği), MDS-UPDRS (Movement Disorder Society-Sponsored Revision of the Unified PD Rating ScaleHareket Bozuklukları Derneği Sponsorlu Revize Birleşik PH Değerleme Ölçeği) ve Hoehn\&Yahr değerleme ölçeğidir.

Bu çalışmada Parkinson hastaları ile sağlıklı bireylerin yürüyüş verileri bulanık tekrarlılık grafiği yöntemi ile incelenmiştir. Yürüyüş sinyalleri dokusal bilgiler içeren resme dönüştürülerek gri seviyeli eş-zamanlılık matrisi yöntemiyle çeşitli parametreler hesaplanmıştır. Hesaplanan parametrelerin PH değerleme ölçekleri ile ilişkisi farklı açılardan detaylı olarak araştırılmıştır. Bu çalışmanın yenilikçi yanı yürüyüş değişkenliği ile PH’nin derecesi arasındaki ilişkinin hesaplamalı yöntemlerle ortaya konmasıdır.

\section{Materyal ve Metot}

\section{1. Önerilen Yöntem ve Veri Seti}

$\mathrm{Bu}$ çalışmada önerilen yöntem Şekil 1 'de verilmiştir. Parkinson hastaları ve sağlıklı bireylerden alınan yürüyüş verileri tek boyutlu zaman serisi şeklinde olup bulanık tekrarlılık grafiği yöntemi ile sinyaller görselleştirilmiştir. Elde edilen siyah beyaz görüntülerden gri seviye eş zamanlılık matrisleri oluşturularak otokorelasyon, kontrast, korelasyon, küme önceliği, küme gölgesi, 
benzeşmezlik, enerji, entropi, homojenlik ve maksimum olasılık parametreleri hesaplanmıştır. Hesaplanan parametrelerin hastalık değerleme ölçekleri ile olan ilişkisi istatistiksel yöntemlerle incelenmiştir.

Çalışmada kullanılan veri seti (Frenkel-Toledo et al., 2005; Frenkel-Toledo et al., 2005; Hausdorff et al., 2007; Yogev et al., 2005) 'da elde edilmiş olup, erişime açıktır (Goldberger AL, 2003). Bu veri setinde 93 Parkinson hastasının (ortalama yaş: 66,3 yıl;\% 63 erkek) ve 73 sağlıklı bireyin (ortalama yaş: 66,3 yıl;\% 55 erkek) toplamda 306 adet yürüme ölçümlerini içermektedir. Deneklerin her iki ayaklarının altında bulunan 8 sensör (Ultraflex Computer Dyno Graphy, Infotronic Inc.), uygulanan basınç kuvvetini Newton cinsinden zamanın bir fonksiyonu olarak kaydetmektedir.

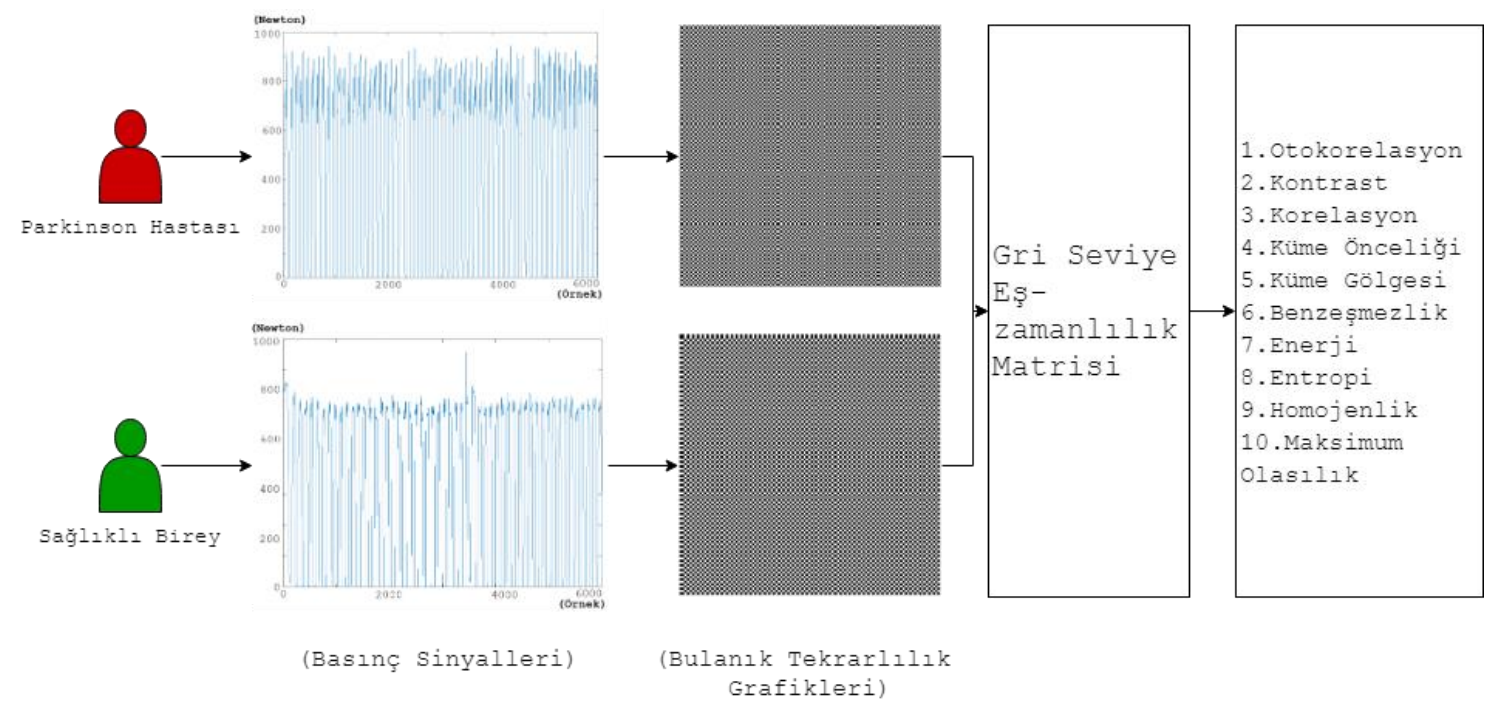

Şekil 1. Çalışma için önerilen sistem

Toplamda 16 adet sensörden elde edilen veriler $100 \mathrm{~Hz}$ ile örneklenmektedir. Sensör lokasyonları $(\mathrm{X}, \mathrm{Y})$ koordinat düzlemine göre deneklerin pozitif Y eksenine dönük ve ayakların birbirine paralel olduğu durumda orta nokta $(0,0)$ olarak kabul edilerek Tablo 1'de verilmiştir. Bu çalışma için sol ayakta bulunan 8 adet sensörün toplam verisi kullanılmıştır. Parkinson hastası ve sağlıklı birey için elde edilen örnek sinyaller Şekil 2'de verilmiştir.

Tablo 1. Sensör lokasyonları

\begin{tabular}{|c|c|c|c|}
\hline Sensör & $(\mathbf{X}, \mathbf{Y})$ & Sensör & $(\mathbf{X , Y})$ \\
\hline Sol 1 & $(-500,-800)$ & Sağ 1 & $(500,-800)$ \\
\hline Sol 2 & $(-700,-400)$ & Sağ 2 & $(700,-400)$ \\
\hline Sol 3 & $(-300,-400)$ & Sağ 3 & $(300,-400)$ \\
\hline Sol 4 & $(-700,0)$ & Sağ 4 & $(700,0)$ \\
\hline Sol 5 & $(-300,0)$ & Sağ 5 & $(300,0)$ \\
\hline Sol 6 & $(-700,400)$ & Sağ 6 & $(700,400)$ \\
\hline Sol 7 & $(-300,400)$ & Sağ 7 & $(300,400)$ \\
\hline Sol 8 & $(-500,800)$ & Sağ 8 & $(500,800)$ \\
\hline
\end{tabular}

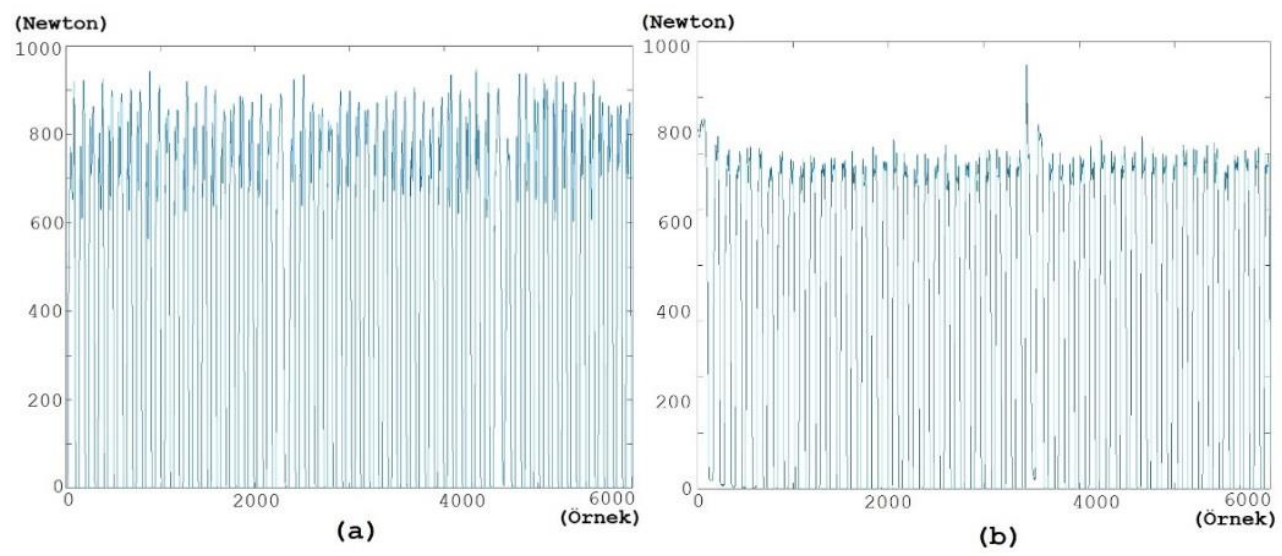

Şekil 2. (a) Parkinson hastası ve (b) sağllklı birey için sol ayakta bulunan 8 adet sensörden toplam olarak elde edilen sinyaller 


\subsection{PH Değerleme Ölçekleri}

UPDRS, PH'den kaynaklı olarak yaşanan bozulma ve kayıpların kapsamlı ve etkin bir şekilde izlenebilmesi için önceden var olan hastalığı değerleme ölçeklerinin birleştirilmesi ile 1980 yllında geliştirilmiştir (Fahn \& Elton, 1987). Bu ölçekleme dört kısımdan oluşmaktadır: (i) Mentasyon, davranış ve ruh hali (ii) Günlük yaşam aktiviteleri (iii) Motor (iv) Komplikasyonlar (Disease, 2003). Belirtilen kısımların altlarında çeşitli alt başlıklar bulunmaktadır. Bu başlıklar için 0 ile 4 arasında ( $0=$ normal, 1=zayıf, 2=hafif, $3=$ orta, 4=şiddetli) değer hesaplanmaktadır. Dördüncü kısımda ise evet/hayır seçenekli sorular yer almaktadır.

MDS-UPDRS, UPDRS' de mevcut olan belirsizlikleri ortadan kaldıracak ve güncel bilimsel gelişmeleri içerecek şekilde revize edilmiş ş̧eklidir. UPDRS' de 42 (soru dağılımı: (i)4, (ii)13, (iii)14, (iv)11) olan soru sayısı MDS-UPDRS' de 50' ye (soru dağılımı: (i)13, (ii)13,(iii)18, (iv)6) çıkarılmıştır. MDS-UPDRS' de evet/hayır seçenekli sorular yapısal tutarsızlığa neden olduğu için kaldırılarak tüm sorular için 0 ile 4 arasında puanlandırılmıștır (Goetz et al., 2007; Goetz et al., 2008).

Hoehn\&Yahr değerleme ölçeği (Hoehn \& Yahr, 1967) hastalıktan dolayı yaşanan fonksiyon bozukluklarını ve objektif bulguları birleştirerek PH'nin derecesini değerlendirmek için kullanılır. Orijinalinde beş puanlık ölçek (1-5) ile değerlendirilirken, revize edilerek 0,5'lik artışlarla ara seviyeler oluşturulmuştur. Bu seviyelerin ifade ettiği evreler şu şekildedir: (i) 1,0: Tek taraflı tutulum, (ii) 1,5: Tek taraflı ve aksiyel tutulum, (iii)2,0: Çift taraflı tutulum, denge kaybı yok, (iv)2,5: Çekme testinde düzelme ile hafif şiddette iki taraflı hastalık, (v)3,0: Orta şiddette iki taraflı hastalık, bazı postüral instabilite, fiziksel olarak bağımsız, (vi)4,0: Şiddetli hastalık, yardımsız yürüme ve kalkma, (vii)5,0: Yatalak veya tekerlekli sandalyeye bağlı (Goetz et al., 2004).

\subsection{Bulanık Tekrarlılık Grafĭgi}

Bulanık tekrarlılık grafiği ile zaman serisi şeklindeki verilerin, dokusal bilgiler içeren resme dönüştürülmesi sağlanır. Bulanık tekrarlılık grafiği yöntemi, Pham (T. Pham, 2017) tarafından önerilmiş olup, tekrarlılık grafiğinin (Eckmann et al., 1995) geliştirilmiş halidir. Bulanık tekrarlılık grafiği yöntemi ile tek boyutlu sinyallerin iki boyutlu sinyallere dönüşümü aşağıdaki şekilde özetlenebilir (T. Pham, 2017; T. D. Pham, 2017):

$X=\{x\}, m$ boyuta sahip zaman serisi verisi olup, zaman serisinin $i$. değeri $x_{i}$ olarak belirtilmektedir. Bulanık tekrarlılık grafiği, $N x N$ boyutlarında kare matris olup matris içerisindeki veriler $(i, j)$ olarak adreslemektedir. Burada $i=1, \ldots, N, j=1, \ldots, N$ ve $(i, j) \in$ $\{0,1\}$ olmalıdır. Bulanık tekrarlılık grafiği için $V=\{v\}, X^{\prime}$ in bulanık kümesi olup, bulanık k-ortalamalar kümesi yöntemi (Bezdek et al., 1984) kullanılarak hesaplanır. $X$ ile $V$ arasındaki bulanık ilişki $R=X x V$ ile gösterilmekte olup, bulanık üyelik fonksiyonu $\mu \in$ $[0,1]$ ile değerlendirilmektedir. $\mu, R$ içerisindeki her bir $(x, v)$ çiftinin yakınlığını derecelendirmek için kullanılır. $\mu$ fonksiyonun özellikleri şunlardır:

(i) Refleksivite: $\mu(x, x)=1, \forall x \in X$,

(ii) Simetri: $\mu(x, v)=\mu(v, x), \forall x \in X, \forall v \in V$

(iii) Geçişlilik: $\mu(x, z)=v_{v}[\mu(x, v) \wedge \mu(v, z)], \forall x \in X, \forall z \in Z$, burada $\vee$ ve $\wedge$ sırasıyla maksimum ve minimumu göstermek için kullanılmıştır.

Bulanık kümeler oluşturulduktan sonra bulanık küme merkezleri ile ilgili zaman verisi arasındaki ilişkinin gücü hesaplanır. $\left\{x_{1}, x_{2}, \ldots, x_{N}\right\}$ faz-uzay durumları olarak varsayılırsa, bulanık k-ortalamalar kümesi yöntemi Eş. 1'de ifade edilen bulanık objektif fonksiyonu en aza indirmek için kullanılır.

$$
J(U, Z)=\sum_{i=1}^{N} \sum_{j=1}^{c}\left(\mu_{i j}\right)^{\omega}\left[d\left(x_{i}, z_{j}\right)\right]^{2}
$$

Burada $c$ küme sayısını, $1<c<N, \omega$ bulanık ağırlık üssünü, $\omega \in[1, \infty], U=\left[\mu_{i j}\right]$ bulanık c-bölüm matrisini, $i=1, \ldots, N, j=$ $1, \ldots, c, \quad Z$ küme merkezlerinin vektörünü, $Z=\left(z_{1}, z_{2}, \ldots, z_{c}\right)$ göstermektedir. $j$. küme merkezi $z_{j}$ olup iç çarpım kaynaklı norm metrik $d\left(x_{i}, z_{j}\right)$ ' dir. Eş. 1, Eş. 2'ye bağımlı olup aşağıda verilmiştir.

$$
\sum_{j=1}^{c} \mu_{i j}=1, i=1, \ldots, N ; j=1, \ldots, c ; \mu_{i j} \in[1, \infty]
$$

$J(U, Z)$ fonksiyonunu minimuma ulaştırmak için, $U$ ve $Z$ durma şartı sağlanıncaya kadar tekrarlı olarak güncellenir. $U$ ve $Z$ için güncelleme denklemleri Eş. 3 ve Eş. 4 'te sirasıyla verilmiştir.

$$
\begin{gathered}
\mu_{i j}=1 / \sum_{j=1}^{c}\left[\frac{d\left(x_{i}, z_{k}\right)}{d\left(x_{i}, z_{j}\right)}\right]^{2 /(\omega-1)}, 1 \leq k \leq c \\
z_{j}=\frac{\sum_{i=1}^{N}\left(\mu_{i j}\right)^{\omega} x_{i}}{\sum_{i=1}^{N}\left(\mu_{i j}\right)^{\omega}}, \forall j
\end{gathered}
$$


Durma şartı $\left\|U^{t}-U^{t+1}\right\| \leq \kappa$ olarak verilmekte olup burada $t$ iterasyon sayısını belirtmektedir. $\kappa$ ise küçük pozitif gerçek bir sayı olup minimum iyileşme seviyesini göstermektedir. Parkinson hastası ve sağlıklı birey için elde edilen bulanık tekrarlılık grafikleri Şekil 3 'te verilmiştir.

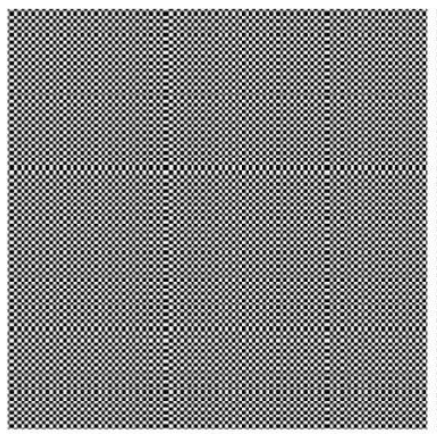

(a)

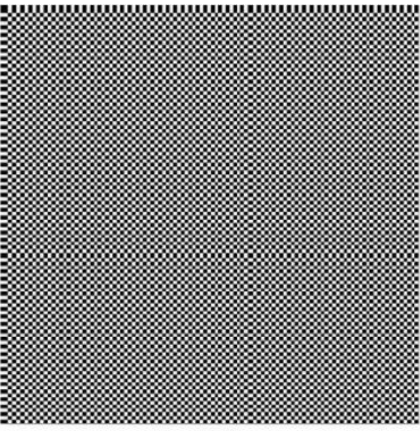

(b)

Şekil 3. (a) Parkinson hastası ve (b) săglıklı birey için bulanık tekrarlılık grafikleri

\subsection{Gri Seviye Eş-zamanlılık Matrisi}

Gri seviye eş-zamanlılık matrisi (Haralick \& Shanmugam, 1973) bir görüntünün piksellerini belirlenmiş gri düzeylerin bir fonksiyonu olarak temsil etmek için kullanılır. $\mathrm{N}_{\mathrm{x}}$ sütun ve $\mathrm{N}_{\mathrm{y}}$ satır sayısına sahip bir resimde, her bir pikselde gözlemlenen gri seviye $\mathrm{N}_{\mathrm{g}}$ seviyeye kuantalanır. $\mathrm{L}_{\mathrm{x}}=\left\{1,2, \ldots, \mathrm{N}_{\mathrm{x}}\right\}$ sütunları, $\mathrm{L}_{\mathrm{y}}=\left\{1,2, \ldots, \mathrm{N}_{\mathrm{y}}\right\}$ satırları ve $\mathrm{G}_{\mathrm{x}}=\left\{0,1, \ldots, \mathrm{N}_{\mathrm{g}}-1\right\}$ kuantalanmış $\mathrm{N}_{\mathrm{g}}$ gri seviyelerin kümesini göstermektedir. $\mathrm{L}_{\mathrm{x}} \times \mathrm{L}_{\mathrm{y}}$ resmin piksel kümeleri olup satır-sütun atamalarına göre sıralanmaktadır. I resmi, her bir piksele veya $L_{x} \times L_{y}\left(I: L_{x} \times L_{y} \rightarrow G\right)$ içerisindeki koordinat çiftlerine $G$ içerisindeki bazı gri seviyeleri atayan bir fonksiyon ile temsil edilebilir. Doku bilgisi, aralarında d kadar uzaklık bulunan iki komşu pikselin bağıl frekans matrisi $\mathrm{P}_{\mathrm{ij}}$ ile belirtilir. Bu piksellerden birinin gri seviyesi i olup, diğer pikselin gri seviyesi j' dir.

Bu çalışmada gri seviye eş-zamanlılık matrisinden hesaplanan parametreler: otokorelasyon (Soh \& Tsatsoulis, 1999), kontrast (Soh \& Tsatsoulis, 1999), korelasyon (Soh \& Tsatsoulis, 1999), küme önceliği (Soh \& Tsatsoulis, 1999), küme gölgesi (Soh \& Tsatsoulis, 1999), benzeşmezlik (Soh \& Tsatsoulis, 1999), enerji (Soh \& Tsatsoulis, 1999), entropi (Soh \& Tsatsoulis, 1999), homojenlik (Soh \& Tsatsoulis, 1999) ve maksimum olasılık (Soh \& Tsatsoulis, 1999) olup tanımları Tablo 2'de verilmiştir.

Tablo 2. Gri seviye eş-zamanlılık matrisinden hesaplanan parametreler

\begin{tabular}{|l|l|}
\hline Otokorelasyon & $\sum_{i} \sum_{j}(i j) \cdot p(i, j)$ \\
\hline Kontrast & $\sum_{\mathrm{n}=0}^{\mathrm{N}_{\mathrm{g}}-1} \mathrm{n}^{2}\left\{\sum_{\mathrm{i}=1}^{\mathrm{N}_{\mathrm{g}}} \sum_{\mathrm{j}=1}^{\mathrm{N}_{\mathrm{g}}} p(i, j)|| \mathrm{i}-\mathrm{j} \mid=\mathrm{n}\right\}$ \\
\hline Korelasyon & $\frac{\sum_{i} \sum_{j}(i j) \cdot p(i, j)-\mu_{\mathrm{x}} \mu_{\mathrm{y}}}{\sigma_{\mathrm{x}} \sigma_{\mathrm{y}}}$ \\
\hline Küme Önceliği & $\sum_{i} \sum_{j}\left(i+j-\mu_{\mathrm{x}}-\mu_{\mathrm{y}}\right)^{4} \cdot p(i, j)$ \\
\hline Küme Gölgesi & $\sum_{i} \sum_{j}\left(i+j-\mu_{\mathrm{x}}-\mu_{\mathrm{y}}\right)^{3} \cdot p(i, j)$ \\
\hline Benzeşmezlik & $\sum_{i} \sum_{j}|\mathrm{i}-\mathrm{j}| \cdot p(i, j)$ \\
\hline Enerji & $\sum_{i} \sum_{j} p(i, j)^{2}$ \\
\hline Entropi & $-\sum_{i} \sum_{j} p(i, j) \log (p(i, j))$ \\
\hline Homojenlik & $\sum_{i} \sum_{j} \frac{1}{1+(\mathrm{i}-\mathrm{j})^{2}} p(i, j)$ \\
\hline Maksimum Olasılık & $\begin{array}{l}\mathrm{MAX} \\
\mathrm{i}, \mathrm{j}(\mathrm{i}, \mathrm{j})\end{array}$ \\
\hline
\end{tabular}

Burada $p(i, j)$ gri seviye eş-zamanlılık matrisinde $(i, j)$ konumundaki değeri göstermektedir. Sütun için ortalama $\mu_{\mathrm{x}}=$ $\sum_{i} \sum_{j} i . p(i, j) v e$ standart sapma $\sigma_{\mathrm{x}}=\sum_{\mathrm{i}} \sum_{\mathrm{j}}\left(\mathrm{i}-\mu_{\mathrm{x}}\right)^{2} \cdot \mathrm{p}(\mathrm{i}, \mathrm{j})$, satır için ortalama ve standart sapma $\mu_{\mathrm{y}}=\sum_{\mathrm{i}} \sum_{\mathrm{j}} \mathrm{j} \cdot \mathrm{p}(\mathrm{i}, \mathrm{j}) \sigma_{\mathrm{y}}=$ $\sum_{\mathrm{i}} \sum_{\mathrm{j}}\left(\mathrm{j}-\mu_{\mathrm{y}}\right)^{2} \cdot \mathrm{p}(\mathrm{i}, \mathrm{j})$ olarak sirasiyla verilmektedir. 


\section{5. İstatistiksel Yöntemler}

Gri seviye eş-zamanlılık matrisinden hesaplanan parametrelerin anlamlılı̆̆ istatistiksel yöntemlerle incelenmiştir. Bu istatiksel testler parametrelerden elde edilen verilerin PH'nin derecesi ile olan ilişkisinin anlamlı olup olmadığını belirtmektedir.

Pearson korelasyon katsayısı, sürekli olan iki değişken arasında ortak bir ilişki ölçüsüdür ve şu şekilde tanımlanmaktadır (Eş. 5):

$$
\mathrm{r}(\text { Pearson })=\frac{\sum_{\mathrm{i}=1}^{\mathrm{n}}\left(\left(\mathrm{x}_{\mathrm{i}}-\bar{x}\right)\left(\mathrm{y}_{\mathrm{i}}-\bar{y}\right)\right)}{\sqrt{\sum_{\mathrm{i}=1}^{\mathrm{n}}\left(\mathrm{x}_{\mathrm{i}}-\bar{x}\right)^{2} \sum_{\mathrm{i}=1}^{\mathrm{n}}\left(\mathrm{y}_{\mathrm{i}}-\bar{y}\right)^{2}}}
$$

Burada $\mathrm{x}$ ve $\mathrm{y}$ değişkenler olup, $\mathrm{n}$ değişkenlerin uzunluğunu, $\bar{x}$ ve $\bar{y}$ ise ilgili değişkenlerin aritmetik ortalamasını göstermektedir. $r$ (Pearson) katsayıs -1 ile +1 arasında değişmekte olup, -1 mükemmel negatif korelasyonu, +1 mükemmel pozitif korelasyonu, 0 ise iki değişken arasında bağıntı olmadığı gösterir (Chok, 2010).

Spearman korelasyon katsayısı, Pearson'un korelasyon katsayısının sıra tabanlı bir versiyonu olup ifadesi Eş. 6'da verilmiştir.

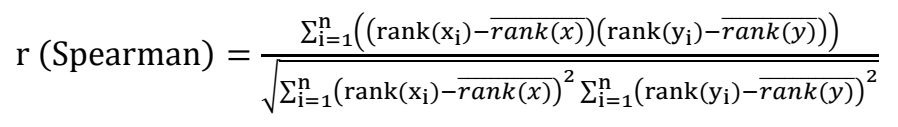

Burada $\operatorname{rank}\left(\mathrm{x}_{\mathrm{i}}\right)$ ve $\operatorname{rank}\left(\mathrm{y}_{\mathrm{i}}\right)$, $\mathrm{x}$ ve $\mathrm{y}$ değişkenlerinin sıralı düzendeki durumlarıdır. $\mathrm{r}$ (Spearman) -1 ile +1 arasında değer üretmekte olup, 0 değeri korelasyon olmadığını belirtmektedir (Chok, 2010).

Kendall korelasyon katsayısı, iki sıralı değişken arasındaki ilişkiyi yakalamak için tasarlanmıştır. Eş. 7'de ifadesi verilmiştir.

$$
\tau(\text { Kendall })=\frac{\sum_{\mathrm{i}=1}^{\mathrm{n}} \sum_{\mathrm{j}=1}^{\mathrm{n}} \operatorname{sgn}\left(\mathrm{x}_{\mathrm{i}}-\mathrm{x}_{\mathrm{j}}\right) \operatorname{sgn}\left(\mathrm{y}_{\mathrm{i}}-\mathrm{y}_{\mathrm{j}}\right)}{\mathrm{n}(\mathrm{n}-1)}
$$

Burada :

$\operatorname{sgn}\left(x_{i}-x_{j}\right)=\left\{\begin{array}{r}1, \text { Ĕger }\left(x_{i}-x_{j}\right)>0 \\ 0, \text { Ĕger }\left(x_{i}-x_{j}\right)=0, \\ -1, \text { Ĕger }\left(x_{i}-x_{j}\right)<0\end{array}\right.$
$\operatorname{sgn}\left(y_{i}-y_{j}\right)=\left\{\begin{array}{r}1, \text { Ĕger }\left(y_{i}-y_{j}\right)>0 \\ 0, \text { Ĕger }\left(y_{i}-y_{j}\right)=0 \\ -1, \text { Ĕger }\left(y_{i}-y_{j}\right)<0\end{array}\right.$

olarak belirtilmekte olup, Kendall korelasyon katsayısı -1 ile +1 arasında değer üretmektedir (Chok, 2010).

\section{Araştırma Sonuçları ve Tartışma}

Gri seviye eş-zamanlılık matrisi kullanılarak hesaplanan parametrelerin UPDRS derecelendirmesine göre dağılımı Şekil 4'te verilmiştir. Farklı parametreler için farklı dağılımlar oluştuğu grafikten gözlemlenmektedir. Bu grafiğin oluşturulmasında sadece Parkinson hastalarının verileri kullanılmış olup sağlıklı bireyler dahil edilmemiştir. Korelasyon, küme gölgesi ve homojenlik haricindeki parametreler UPDRS derecelendirmesine göre grafikte farklı bölgelere dağılmışlardır. Bu dağılım grafiği, ilgili parametrelerin değerlerinin hastalığın derecesine göre değiştiğini göstermektedir.
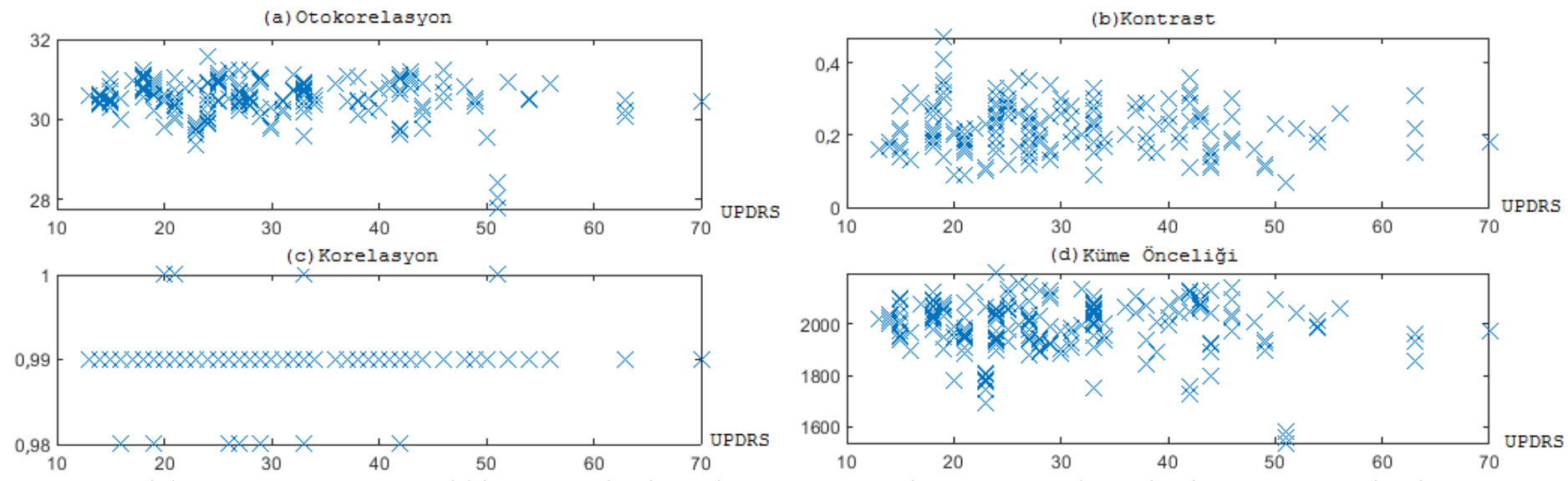

Şekil 4. Gri seviye eş-zamanlllık matrisinden hesaplanan parametrelerin UPDRS derecelendirmesine göre dă̆gllımı 

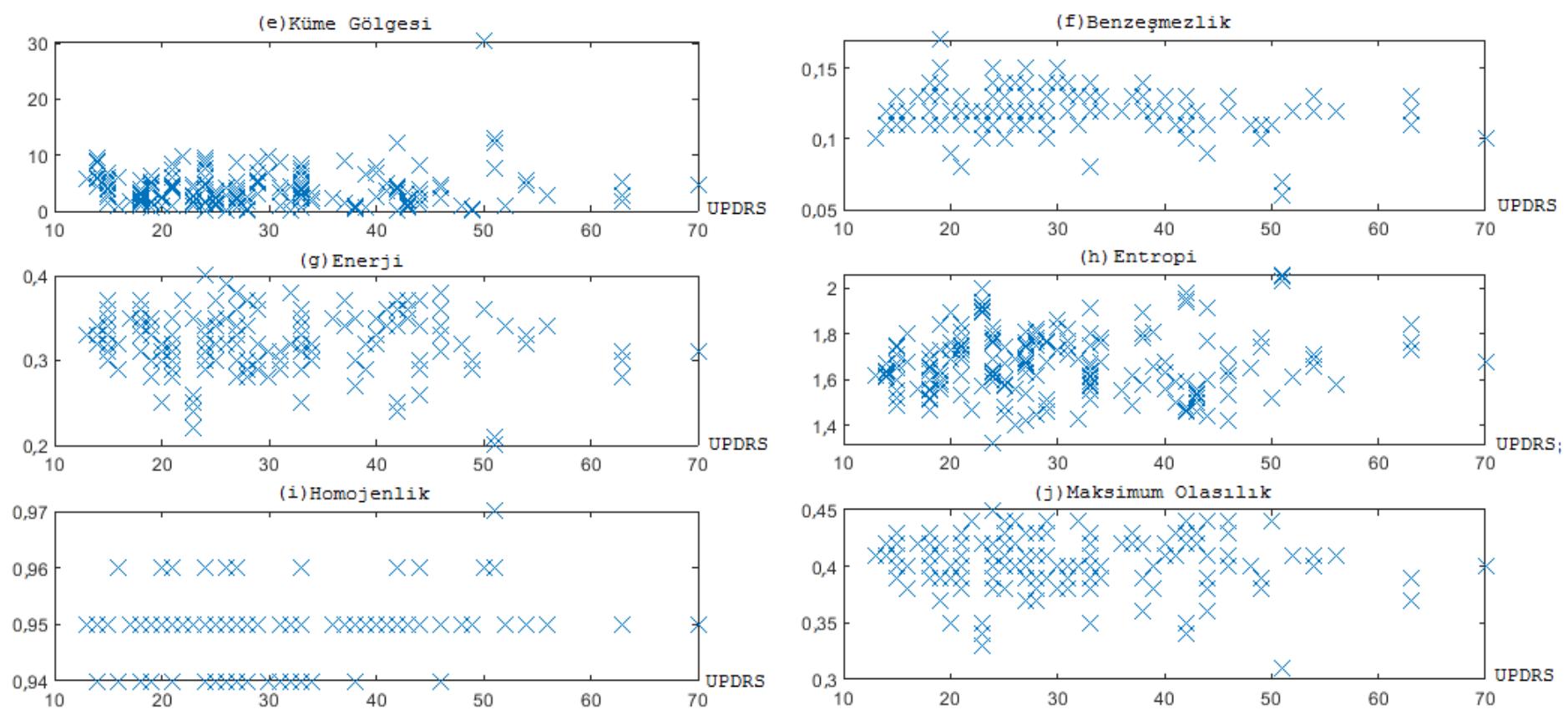

Şekil 4. Gri seviye eş-zamanlıllk matrisinden hesaplanan parametrelerin UPDRS derecelendirmesine göre dăğlımı (devamı)

Tablo 3'te hesaplanan parametrelerin UPDRS derecelendirmesine bağlı istatistiksel analiz sonuçları gösterilmiştir. Buna göre entropi sonucu ile UPDRS derecelendirmesi arasında pozitif korelasyon bulunmaktadır. Hesaplanan p değerleri korelasyon, küme gölgesi ve homojenlik haricindeki parametrelerin değişiminin UPDRS derecelendirmesi ile istatiksel olarak anlamlı $(\mathrm{p}<0,05)$ olduğunu ortaya koymaktadır.

Tablo 3. Hesaplanan parametrelerin UPDRS derecelendirmesine bağll istatistiksel analizi

\begin{tabular}{|l|c|c|c|c|}
\hline & $r$ (Pearson) & $r$ (Spearman) & $\tau$ (Kendal) & $p$ \\
\hline Otokorelasyon & $-0,27$ & $-0,21$ & $-0,15$ & $\mathrm{p}<0,05$ \\
\hline Kontrast & $-0,12$ & $-0,07$ & $-0,05$ & $\mathrm{p}<0,05$ \\
\hline Korelasyon & 0,09 & 0,07 & 0,06 & $1,2 \times 10^{-1}$ \\
\hline Küme Önceliği & $-0,26$ & $-0,20$ & $-0,14$ & $\mathrm{p}<0,05$ \\
\hline Küme Gölgesi & 0,04 & $-0,05$ & $-0,04$ & $4,9 \times 10^{-1}$ \\
\hline Benzeşmezlik & $-0,15$ & $-0,08$ & $-0,06$ & $\mathrm{p}<0,05$ \\
\hline Enerji & $-0,25$ & $-0,20$ & $-0,14$ & $\mathrm{p}<0,05$ \\
\hline Entropi & 0,24 & 0,20 & 0,15 & $\mathrm{p}<0,05$ \\
\hline Homojenlik & 0,01 & 0,003 & 0,003 & $8,1 \times 10^{-1}$ \\
\hline Maksimum Olasılık & $-0,23$ & $-0,18$ & $-0,14$ & $\mathrm{p}<0,05$ \\
\hline
\end{tabular}

Tablo 4'te hesaplanan parametrelerin MDS-UPDRS derecelendirmesine bağlı istatistiksel analiz sonuçları gösterilmiştir. Tabloya göre ilgili p değerleri, kontrast, korelasyon, küme gölgesi ve homojenlik parametrelerinin değişimlerinin MDS-UPDRS derecelendirmesine göre istatistiksel olarak anlamsız olduğunu göstermektedir. Entropi sonucu pozitif korelasyon belirtirken, istatistiksel olarak anlamlı $(\mathrm{p}<0,05)$ olan diğer parametreler negatif korelasyona sahiptir.

Tablo 4. Hesaplanan parametrelerin MDS-UPDRS derecelendirmesine bağll istatistiksel analizi

\begin{tabular}{|l|c|c|c|c|}
\hline & $r$ (Pearson) & $r($ Spearman) & $\tau$ (Kendal) & $p$ \\
\hline Otokorelasyon & $-0,26$ & $-0,23$ & $-0,17$ & $\mathrm{p}<0,05$ \\
\hline Kontrast & $-0,09$ & $-0,07$ & $-0,05$ & $1,1 \times 10^{-1}$ \\
\hline Korelasyon & 0,02 & 0,01 & 0,01 & $6,9 \times 10^{-1}$ \\
\hline Küme Önceliği & $-0,26$ & $-0,22$ & $-0,16$ & $\mathrm{p}<0,05$ \\
\hline Küme Gölgesi & 0,04 & $-0,04$ & $-0,03$ & $5,2 \times 10^{-1}$ \\
\hline Benzeşmezlik & $-0,13$ & $-0,11$ & $-0,08$ & $\mathrm{p}<0,05$ \\
\hline Enerji & $-0,25$ & $-0,21$ & $-0,16$ & $\mathrm{p}<0,05$ \\
\hline Entropi & 0,25 & 0,22 & 0,16 & $\mathrm{p}<0,05$ \\
\hline Homojenlik & 0,02 & 0,02 & 0,02 & $7,7 \times 10^{-1}$ \\
\hline Maksimum Olasılık & $-0,24$ & $-0,20$ & $-0,15$ & $\mathrm{p}<0,05$ \\
\hline
\end{tabular}


Tablo 5' te Gri seviye eş-zamanlılık matrisinden hesaplanan parametrelerin Hoehn\&Yahr derecelendirmesine bağlı istatistiksel analiz sonuçları verilmiştir. Buna göre otokorelasyon, kontrast, küme önceliği, enerji, homojenlik ve maksimum olasılık sonuçları ile Hoehn\&Yahr derecelendirmesi arasında negatif ilişki vardır. Entropi sonucu ise pozitif korelasyon belirtmektedir. Hesaplanan p değerlerine göre korelasyon, küme gölgesi ve benzeşmezlik haricindeki parametrelerin değişimi ile Hoehn\&Yahr derecelendirmesi arasındaki ilişki istatiksel olarak anlamlıdır $(\mathrm{p}<0,05)$.

Tablo 5. Hesaplanan parametrelerin Hoehn\&Yahr derecelendirmesine bağlı istatistiksel analiz sonuçları

\begin{tabular}{|l|c|c|c|c|}
\hline & $r$ (Pearson) & $r$ (Spearman) & $\tau$ (Kendal) & $p$ \\
\hline Otokorelasyon & $-0,30$ & $-0,33$ & $-0,26$ & $\mathrm{p}<0,05$ \\
\hline Kontrast & $-0,17$ & $-0,22$ & $-0,17$ & $\mathrm{p}<0,05$ \\
\hline Korelasyon & 0,09 & 0,15 & 0,14 & $1,3 \times 10^{-1}$ \\
\hline Küme Önceliği & $-0,31$ & $-0,33$ & $-0,25$ & $\mathrm{p}<0,05$ \\
\hline Küme Gölgesi & 0,02 & $-0,06$ & $-0,04$ & $6,9 \times 10^{-1}$ \\
\hline Benzeşmezlik & $-0,09$ & $-0,08$ & $-0,07$ & $1,4 \times 10^{-1}$ \\
\hline Enerji & $-0,31$ & $-0,32$ & $-0,25$ & $\mathrm{p}<0,05$ \\
\hline Entropi & 0,32 & 0,34 & 0,27 & $\mathrm{p}<0,05$ \\
\hline Homojenlik & $-0,14$ & $-0,16$ & $-0,15$ & $\mathrm{p}<0,05$ \\
\hline Maksimum Olasılık & $-0,29$ & $-0,30$ & $-0,25$ & $\mathrm{p}<0,05$ \\
\hline
\end{tabular}

Sadece Parkinson hastalarının değerlendirildiği durum ile Parkinson hastaları ve sağlıklı bireylerin beraber değerlendirildiği durumlarda gri seviye eş-zamanlılık matrisinden hesaplanan parametrelerin Hoehn\&Yahr, UPDRS, MDS-UPDRS derecelendirmeleri ile ilişkisi Şekil 5'te verilmiştir. Buna göre UPDRS ve MDS-UPDRS derecelendirmelerinin parametrelere göre değişimi benzer olmakla birlikte, korelasyon parametresi için elde edilen katsayı UPDRS için daha yüksektir. Hoehn\&Yahr derecelendirmesi için kontrast, korelasyon, küme önceliği ve benzeşmezlik parametreleri, Parkinson hastalarının sağlıklı bireyler ile beraber değerlendirildiği durumda daha yüksek sonuçlar vermiştir. UPDRS ve MDS-UPDRS derecelendirmesi için, homojenlik ve benzeşmezlik parametrelerinde, Parkinson hastaları ile sağlıklı bireylerin beraber değerlendirildiği durum için daha yüksek r katsayısı elde edilmesine rağmen; maksimum olasılık, entropi, enerji, küme önceliği ve otokorelasyon parametrelerinde sadece Parkinson hastalarının değerlendirildiği durum için daha yüksek $r$ değeri elde edilmiştir.

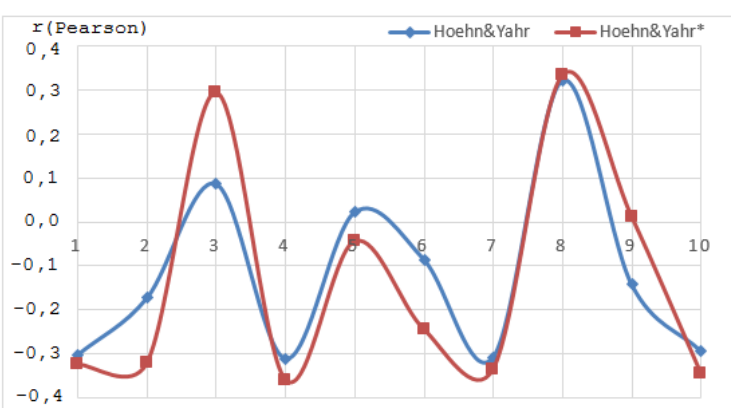

(a)

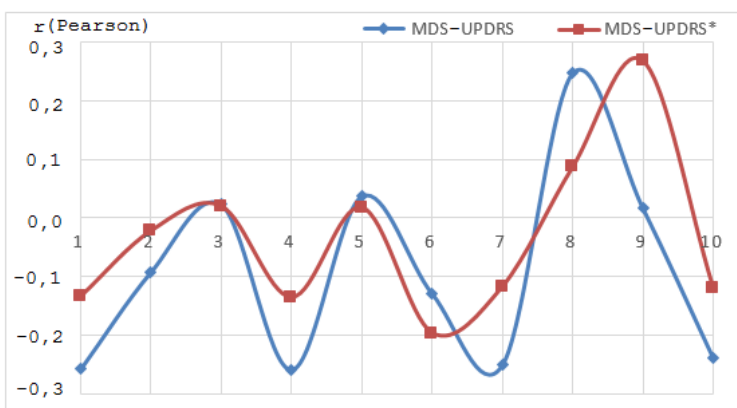

(c)

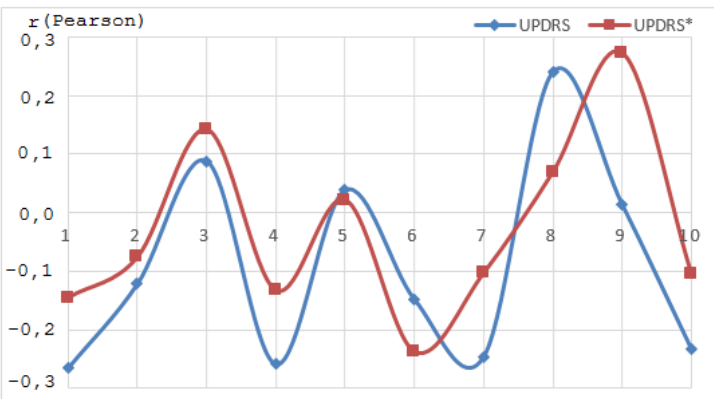

(b)

1. Otokorelasyon

2. Kontrast

2. Kontrast

4. Küme Önceliği

5. Küme Gölgesi

6. Benzeșmezlik

7. Enenzji

.Entropi

9. Homojenlik

10.Maksimum Olasılık

*Parkinson Hastaları + Sağlıklı Bireyler

Şekil 5. Sadece Parkinson hastalarının değerlendirildiği durum ile Parkinson hastaları ve să̆lıklı bireylerin beraber değerlendirildiği durumlarda gri seviye eş-zamanlllık matrisinden hesaplanan parametrelerin (a) Hoehn\&Yahr (b) UPDRS (c) MDS-UPDRS derecelendirmeleri ile ilişkisi

Şekil 6'da sadece Parkinson hastalarının değerlendirildiği durum ile Parkinson hastaları ve sağlıklı bireylerin beraber değerlendirildiği durumlarda, Hoehn\&Yahr, UPDRS ve MDS-UPDRS derecelendirmelerinin hesaplanan parametrelere göre karşılaştırılması verilmiştir. Şekil 6(a)'da sadece Parkinson hastaları değerlendirilmiş olup bütün parametreler için üç derecelendirme yönteminde de yakın $r$ katsayıları elde edilmiştir. En yüksek r katsayıları otokorelasyon, küme önceliği, enerji, entropi ve maksimum olasılık için elde edilmiştir. Şekil 6(b)'de Parkinson hastaları ile sağlıklı bireyler beraber değerlendirilmiş olup, genel anlamda 
Hoehn\&Yahr derecelendirmesi için daha yüksek değerler elde edilmiştir. En yüksek $r$ katsayıları ise otokorelasyon, kontrast, korelasyon, küme önceliği, enerji, entropi ve maksimum olasılık için elde edilmiştir.

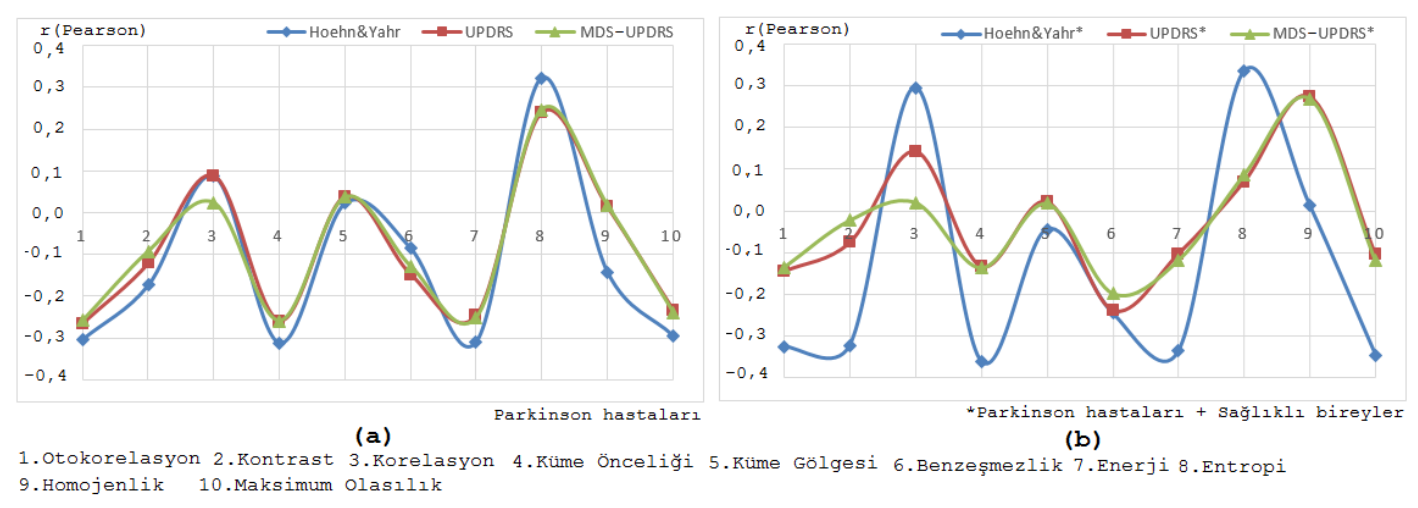

Şekil 6. (a) Sadece Parkinson hastalarının değerlendirildiği durum ile (b) Parkinson hastaları ve să̆lıklı bireylerin beraber değerlendirildiği durumlarda Hoehn\&Yahr, UPDRS ve MDS-UPDRS derecelendirmelerinin hesaplanan parametrelere göre karşılaştırılması

\section{Sonuç}

PH'nin derecesi ile yürüyüş değişkenliği arasındaki ilişki incelenmiştir. Yürüme sinyalleri bulanık tekrarlılık grafiği yöntemi ile görselleştirilerek gri seviye eş-zamanlılık matrisinden otokorelasyon, kontrast, korelasyon, küme önceliği, küme gölgesi, benzeşmezlik, enerji, entropi, homojenlik ve maksimum olasılık parametreleri hesaplanmıştır. Hesaplanan parametrelerin UPDRS, MDS-UPDRS ve Hoehn\&Yahr değerleme ölçekleri ile ilişkisi analiz edilmiştir. Buna göre otokorelasyon, küme önceliği, enerji, entropi ve maksimum olasılık parametrelerinin tüm değerleme ölçekleri ile korele olduğu saptanmıştır. Bunlardan entropi pozitif korelasyon gösterirken, diğerleri negatif korelasyona sahiptir. Korelasyon ve küme gölgesi parametrelerinin ise üç değerleme ölçeği ile de ilişkisi olmadığı belirlenmiştir. Hoehn\&Yahr değerleme ölçeğinin diğer ölçeklere göre genel anlamda daha yüksek sonuçlar ortaya koyması ayırt ediciliğinin daha fazla olduğunu ortaya koymaktadır.

Bu çalışmanın yenilikçi yanı yürüyüş verisi ile PH'nin derecesi arasındaki ilişkinin hesaplamalı yöntemlerle ortaya çıkarılması ve detaylı olarak incelenmesidir. Bulanık tekrarlılık grafiği yöntemi, Parkinson hastası ve sağlıklı bireylerin sınıflandırılmasında kullanılmasına rağmen (T. D. Pham, 2017), PH'nin derecesinin incelenmesi açısından kullanımı yenilikçi bir yaklaşımdır. Bu çalışmada elde edilen sonuçlar, (van der Heeden et al., 2016)' da elde edilen çalışmanın sonuçları ile örtüşmekte ve matematiksel olarak desteklemektedir.

\section{Kaynakça}

Abdulhay, E., Arunkumar, N., Narasimhan, K., Vellaiappan, E., \& Venkatraman, V. (2018). Gait and tremor investigation using machine learning techniques for the diagnosis of Parkinson disease. Future Generation Computer Systems, 83, $366-373$.

Afonso, L. C., Rosa, G. H., Pereira, C. R., Weber, S. A., Hook, C., Albuquerque, V. H. C., \& Papa, J. P. (2019). A recurrence plotbased approach for Parkinson's disease identification. Future Generation Computer Systems, 94, $282-292$.

Aydın, F., \& Aslan, Z. (2017). Yapay öğrenme yöntemleri ve dalgacık dönüşümü kullanılarak nöro dejeneratif hastalıkların teşhisi. Journal of the Faculty of Engineering and Architecture of Gazi University, 32(3), 749-766.

Bezdek, J. C., Ehrlich, R., \& Full, W. (1984). FCM: The fuzzy c-means clustering algorithm. Computers \& Geosciences, 10(2-3), 191-203.

Cantürk, İ. (2020). Fuzzy recurrence plot-based analysis of dynamic and static spiral tests of Parkinson's disease patients. Neural Computing and Applications. https://doi.org/10.1007/s00521-020-05014-2

Cantürk, İ., \& Karabiber, F. (2016). A Machine Learning System for the Diagnosis of Parkinson's Disease from Speech Signals and Its Application to Multiple Speech Signal Types [journal article]. Arabian Journal for Science and Engineering, 41(12), 5049-5059. https://doi.org/10.1007/s13369-016-2206-3

Chaudhuri, K. R., \& Schapira, A. H. (2009). Non-motor symptoms of Parkinson's disease: dopaminergic pathophysiology and treatment. The Lancet Neurology, 8(5), 464-474.

Chok, N. S. (2010). Pearson's versus Spearman's and Kendall's correlation coefficients for continuous data University of Pittsburgh].

Conditions, N. C. C. f. C. (2006). Parkinson's disease: national clinical guideline for diagnosis and management in primary and secondary care.

De Lau, L., Giesbergen, P., De Rijk, M., Hofman, A., Koudstaal, P., \& Breteler, M. (2004). Incidence of parkinsonism and Parkinson disease in a general population: the Rotterdam Study. Neurology, 63(7), 1240-1244.

Disease, M. D. S. T. F. o. R. S. f. P. s. (2003). The unified Parkinson's disease rating scale (UPDRS): status and recommendations. Movement Disorders, 18(7), 738-750.

Eckmann, J., Kamphorst, S. O., \& Ruelle, D. (1995). Recurrence plots of dynamical systems. World Scientific Series on Nonlinear Science Series A, 16, 441-446.

Fahn, S., \& Elton, R. (1987). UPDRS program members. Unified Parkinsons disease rating scale. Recent developments in Parkinson's disease, 2, 153-163.

e-ISSN: 2148-2683 
Frenkel-Toledo, S., Giladi, N., Peretz, C., Herman, T., Gruendlinger, L., \& Hausdorff, J. M. (2005). Effect of gait speed on gait rhythmicity in Parkinson's disease: variability of stride time and swing time respond differently. Journal of neuroengineering and rehabilitation, 2(1), 23.

Frenkel-Toledo, S., Giladi, N., Peretz, C., Herman, T., Gruendlinger, L., \& Hausdorff, J. M. (2005). Treadmill walking as an external pacemaker to improve gait rhythm and stability in Parkinson's disease. Movement disorders: official journal of the Movement Disorder Society, 20(9), 1109-1114.

Goetz, C. G., Fahn, S., Martinez-Martin, P., Poewe, W., Sampaio, C., Stebbins, G. T., Stern, M. B., Tilley, B. C., Dodel, R., \& Dubois, B. (2007). Movement Disorder Society-sponsored revision of the Unified Parkinson's Disease Rating Scale (MDS-UPDRS): process, format, and clinimetric testing plan. Movement Disorders, 22(1), 41-47.

Goetz, C. G., Poewe, W., Rascol, O., Sampaio, C., Stebbins, G. T., Counsell, C., Giladi, N., Holloway, R. G., Moore, C. G., \& Wenning, G. K. (2004). Movement Disorder Society Task Force report on the Hoehn and Yahr staging scale: status and recommendations the Movement Disorder Society Task Force on rating scales for Parkinson's disease. Movement Disorders, 19(9), 1020-1028.

Goetz, C. G., Tilley, B. C., Shaftman, S. R., Stebbins, G. T., Fahn, S., Martinez-Martin, P., Poewe, W., Sampaio, C., Stern, M. B., \& Dodel, R. (2008). Movement Disorder Society-sponsored revision of the Unified Parkinson's Disease Rating Scale (MDS-UPDRS): scale presentation and clinimetric testing results. Movement disorders: official journal of the Movement Disorder Society, 23(15), 2129-2170.

Goldberger AL, A. L., Glass L, Hausdorff JM, Ivanov PCh, Mark RG, Mietus JE, Moody GB, Peng C-K, Stanley HE. (2003). PhysioBank, PhysioToolkit, and PhysioNet: Components of a New Research Resource for Complex Physiologic Signals. Circulation, 101(23), e215-e220.

Gündüz, H. Parkinson Hastalığı Tespitinde Farklı Boyutsallık İndirgeme Yöntemlerinin Karşılaştırılması. Avrupa Bilim ve Teknoloji Dergisi(17), 1164-1172.

Haralick, R. M., \& Shanmugam, K. (1973). Textural features for image classification. IEEE Transactions on systems, man, and cybernetics(6), 610-621.

Hausdorff, J. M., Lowenthal, J., Herman, T., Gruendlinger, L., Peretz, C., \& Giladi, N. (2007). Rhythmic auditory stimulation modulates gait variability in Parkinson's disease. European journal of neuroscience, 26(8), 2369-2375.

Hoehn, M. M., \& Yahr, M. D. (1967). Parkinsonism: onset, progression, and mortality. Neurology, 17(5), $427-427$.

Italian, N. S. (2003). Treatment of Parkinson's disease. Neurological sciences: official journal of the Italian Neurological Society and of the Italian Society of Clinical Neurophysiology, 24, S165.

Khatamino, P., Cantürk, İ., \& Özyılmaz, L. (2018). A Deep Learning-CNN Based System for Medical Diagnosis: An Application on Parkinson's Disease Handwriting Drawings. 2018 6th International Conference on Control Engineering \& Information Technology (CEIT),

Naseer, A., Rani, M., Naz, S., Razzak, M. I., Imran, M., \& Xu, G. (2019). Refining Parkinson's neurological disorder identification through deep transfer learning. Neural Computing and Applications, 1-16.

Pham, T. (2017). Fuzzy recurrence plots. EPL (Europhysics Letters), 116(5), 50008.

Pham, T. D. (2017). Texture classification and visualization of time series of gait dynamics in patients with neuro-degenerative diseases. IEEE Transactions on Neural Systems and Rehabilitation Engineering, 26(1), 188-196.

Pham, T. D., \& Yan, H. (2017). Tensor Decomposition of Gait Dynamics in Parkinson's Disease. Ieee Transactions on Biomedical Engineering, 65(8), 1820-1827.

Poewe, W., Seppi, K., Tanner, C. M., Halliday, G. M., Brundin, P., Volkmann, J., Schrag, A.-E., \& Lang, A. E. (2017). Parkinson disease. Nature reviews Disease primers, 3, 17013.

Rao, S. S., Hofmann, L. A., \& Shakil, A. (2006). Parkinson's disease: diagnosis and treatment. Am Fam Physician, 74(12), 20462054.

Sakar, B. E., Isenkul, M. E., Sakar, C. O., Sertbas, A., Gurgen, F., Delil, S., Apaydin, H., \& Kursun, O. (2013). Collection and analysis of a Parkinson speech dataset with multiple types of sound recordings. Ieee Journal of Biomedical and Health Informatics, 17(4), 828-834.

Soh, L.-K., \& Tsatsoulis, C. (1999). Texture analysis of SAR sea ice imagery using gray level co-occurrence matrices. IEEE Transactions on geoscience and remote sensing, 37(2), 780-795.

Tsanas, A., Little, M. A., McSharry, P. E., \& Ramig, L. O. (2010). Accurate telemonitoring of Parkinson's disease progression by noninvasive speech tests. Ieee Transactions on Biomedical Engineering, 57(4), 884-893.

van der Heeden, J. F., Marinus, J., Martinez-Martin, P., Rodriguez-Blazquez, C., Geraedts, V. J., \& van Hilten, J. J. (2016). Postural instability and gait are associated with severity and prognosis of Parkinson disease. Neurology, 86(24), $2243-2250$.

Yogev, G., Giladi, N., Peretz, C., Springer, S., Simon, E. S., \& Hausdorff, J. M. (2005). Dual tasking, gait rhythmicity, and Parkinson's disease: which aspects of gait are attention demanding? European journal of neuroscience, 22(5), 1248-1256.

Yücelbaş, C., \& Yücelbaş, Ş. (2019a). AQDD Özelliklerine BBA Yöntemleri Uygulanarak Parkinson Hastalığının Otomatik Teşhisi. Bilecik Şeyh Edebali Üniversitesi Fen Bilimleri Dergisi, 6.

Yücelbaş, C., \& Yücelbaş, Ş. (2019b). Çift Yoğunluklu 1-D Dalgacık Dönüşümü Kullanılarak Parkinson Hastalığının Yaş Faktörüne Göre Tespit Edilmesi. Avrupa Bilim ve Teknoloji Dergisi(17), 881-887.

Yücelbaş, Ş. (2020). Simple Logistic Hybrid System Based on Greedy Stepwise Algorithm for Feature Analysis to Diagnose Parkinson's Disease According to Gender. Arabian Journal for Science and Engineering, 45(3), 2001-2016.

Yücelbaş, Ş., \& Yücelbaş, C. (2019). Temel Bileşen Analizi Yöntemleri Kullanarak Parkinson Hastalığının Otomatik Teşhisi. Avrupa Bilim ve Teknoloji Dergisi(16), 294-300. 